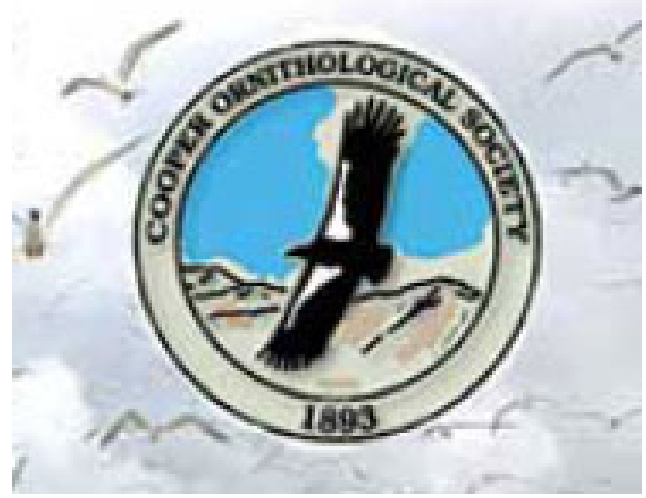

Torpor in Three Species of Brazilian Hummingbirds under Semi-Natural Conditions Author(s): Claus Bech, Augusto S. Abe, John Fleng Steffensen, Martin Berger and Jose Eduardo P. W. Bicudo

Source: The Condor, Vol. 99, No. 3 (Aug., 1997), pp. 780-788

Published by: University of California Press on behalf of the Cooper Ornithological Society

Stable URL: http://www.jstor.org/stable/1370489

Accessed: $15 / 01 / 2014$ 07:54

Your use of the JSTOR archive indicates your acceptance of the Terms \& Conditions of Use, available at

http://www.jstor.org/page/info/about/policies/terms.jsp

JSTOR is a not-for-profit service that helps scholars, researchers, and students discover, use, and build upon a wide range of content in a trusted digital archive. We use information technology and tools to increase productivity and facilitate new forms of scholarship. For more information about JSTOR, please contact support@ jstor.org.

University of California Press and Cooper Ornithological Society are collaborating with JSTOR to digitize, preserve and extend access to The Condor. 


\title{
TORPOR IN THREE SPECIES OF BRAZILIAN HUMMINGBIRDS UNDER SEMI-NATURAL CONDITIONS ${ }^{1}$
}

\author{
Claus Bech \\ Department of Zoology, Norwegian University of Science and Technology, N-7034 Trondheim, Norway, \\ e-mail: clabec@alfa.itea.ntnu.no \\ Augusto S. Abe \\ Departmento de Zoologia, Universidade Estadual Paulista, BR-13506900 Rio Claro, Sp, Brazil
}

JOHN FLENG STEFFENSEN ${ }^{2}$

Department of Zoophysiology, University of Aarhus, DK-8000 Aarhus C., Denmark

MARTIN BERGER

Westfälisches Museum für Naturkunde, D-48161 Münster, Germany

Jose EdUARdo P. W. BICUdo

Universidade de Sao Paulo, Instituto de Biociências, Dept. Fisiol., BR-05508900 Sao Paulo, Brazil

\begin{abstract}
We measured body temperatures in three species of Brazilian hummingbirds, the Versicolored Emerald (Amazilia versicolor; body mass $4.1 \mathrm{~g}$ ), the Black Jacobin $(\mathrm{Me}$ lanotrochilus fuscus; body mass $7.7 \mathrm{~g}$ ) and the Swallow-tailed Hummingbird (Eupetomena macroura; body mass $8.6 \mathrm{~g}$ ), during overnight exposure to natural conditions of photoperiod and ambient temperatures. All three species entered torpor. In both $A$. versicolor and $E$. macroura, individuals entered torpor even if they had access to feeders up to the time of sunset. In contrast, $M$. fuscus was less prone to enter torpor and did so mainly if it had been fasting for more than two hours before sunset. Furthermore, $M$. fuscus often spent the whole night in torpor, whereas the two other species entered torpor for a variable, often short, period of the night. We observed more than one torpor bout during a single night in all three species. We suggest that multiple nocturnal torpors result from interruption of the normal torpor pattern by some (unknown) external stimuli. Any interrupted torpor was always followed by a new entry into torpor, supporting the view that there is a body mass threshold below which the hummingbirds must enter torpor. Our data also indicate that these hummingbird species might use torpor even if they are not energetically stressed.
\end{abstract}

Key words: hummingbirds, Amazilia versicolor, Melanotrochilus fuscus, Eupetomena macroura, torpor, thermoregulation, body temperature.

\section{INTRODUCTION}

For many small homeotherms, daily torpor is an essential mechanism to cope with periods of food deprivation and/or severe weather conditions that pose a challenge to their energetic balance. Torpor is known to occur in birds from at least six different orders (Procellariiformes, Columbiformes, Coliiformes, Caprimulgiformes, Apodiformes, and Trochiliformes; see Reinertsen 1983, Heller 1989, French 1993). Daily torpor has been extensively studied in hummingbirds, in which significant energetic savings are correlated with the use of daily torpor (Hainsworth et al. 1977, 1981, Beuchat et al. 1979,

\footnotetext{
${ }^{1}$ Received 27 June 1996. Accepted 13 March1997.

${ }^{2}$ Current address: Marine Biological Laboratory, University of Copenhagen, DK-3000 Helsingør, Denmark.
}

Hiebert 1990). Most of the studies on hummingbirds suggest that daily torpor is a strategy employed in situations involving energetic stress. Thus, torpor has less often been reported in apparently well-fed individuals (Krüger et al. 1982, Carpenter and Hixon 1988, Hiebert 1993a, 1993b).

Because it is difficult to obtain physiological information from free-living hummingbirds, most studies have been of birds kept under laboratory conditions. Information about the use of torpor under natural conditions in hummingbirds is consequently scarce (Calder and Booser 1973, Carpenter 1974, Calder et al. 1990), as it is for other bird species entering torpor (Brigham 1992). The only study that has provided acceptable proof that hummingbirds need not be energetically stressed in order to resort to daily torpor is that of Carpenter and Hixon (1988), who 
demonstrated torpor in a free-living, well-fed, Rufous Hummingbird Selasphorus rufus. In the same species, but under laboratory conditions, Hiebert (1993a, 1993b) reported increased intensity of torpor during periods of food restriction, but when body mass nonetheless showed an increase. In $S$. rufus the use of torpor was highest in the autumn, suggesting a function of torpor as a strictly energy saving mechanism, thereby minimizing the time required for premigratory fattening. In this case torpor is not correlated with inadequate food intake (Carpenter et al. 1993, Hiebert 1993a). However, it is still an open question whether hummingbirds normally need to be energy-stressed in order to enter torpor under natural conditions (Calder 1994).

We examined the use of torpor by three species of Brazilian hummingbirds kept under seminatural conditions. We asked whether these species would enter torpor under conditions as close to natural as possible. We also wanted to study the influence of short-term changes in their energetic status on the use of torpor. The energetic status of the hummingbirds was manipulated by experimentally depriving them of food from the time of capture until sunset.

\section{METHODS}

The study was carried out at the Museu de Biologia, at Santa Teresa in the state of Espirito Santo, Brazil $\left(19^{\circ} 55^{\prime} \mathrm{S}, 40^{\circ} 36^{\prime} \mathrm{W}\right.$; about $700 \mathrm{~m}$ above sea level). We studied three species of hummingbirds, the Versicolored Emerald Amazilia versicolor $(\sim 4.1 \mathrm{~g})$, the Black Jacobin Melanotrochilus fuscus $(\sim 7.7 \mathrm{~g})$, and the Swallowtailed Hummingbird Eupetomena macroura ( $8.6 \mathrm{~g}$ ). We did not determine sexes in any of the three species, all of which are common breeding birds in the study area (Ruschi 1982).

We conducted the study from 2-20 December 1987. The length of the nights did not vary much, being approximately $11 \mathrm{hr}$ long. Sunrise changed from 05:53 to 05:59 and sunset from 19:10 to 19:19 during the study period. All times are given in Rio de Janeiro summertime.

The hummingbirds in the study area are accustomed to feeding at artificial feeders. Hence, individuals of all three species were easily caught at the feeders during the afternoon. After capture they were kept individually, at normal ambient temperature, in ca. $0.5 \mathrm{~m}^{3}$ cages and deprived of food for a variable time (range 0$240 \mathrm{~min}$ ) until sunset. The birds were weighed
(Mettler, accuracy $0.01 \mathrm{~g}$ ) and then placed individually in smaller overnight cages (approximately $12 \times 12 \times 20$-cm cardboard boxes) provided with a perch. Usually the birds roosted quietly on the perch during the night, although in some cases they apparently had spent the night sitting on the floor of the cage. The cages (up to six used each night) were placed outdoors during the night. The walls and top of each cage were equipped with holes, to ensure that the hummingbirds were exposed to natural variations in both ambient temperature and photoperiod.

The small size of hummingbirds makes the measurement of body temperature $\left(\mathrm{T}_{\mathrm{b}}\right)$ a difficult task. We used a copper-constantan thermocouple (California Fine Wire Company, type 0.005) placed subcutaneously and laterally on the pectoral muscle for measurements of body temperature. The thermocouple was fixed in place with small pieces of adhesive tape. During measurement, the subcutaneously placed tip of the thermocouple was covered by the wing. Pilot studies of all three species indicated that such measurements of pectoral temperature did not differ by more than $0.2-0.3^{\circ} \mathrm{C}$ from simultaneous measurements of rectal temperature. A thermocouple was placed inside one of the cages to record the actual ambient temperature $\left(\mathrm{T}_{\mathrm{a}}\right)$ to which the birds were exposed. All thermocouples were extended by using large-diameter copper-constantan thermocouples (Bicc Cables, U.K., 4-5 m length) that went to a nearby house where the data-acquisition equipment was placed.

Body temperatures were measured every 40 sec throughout the night. The thermocouple wires were connected to a Data Translation (DT 2805) A/D converter, via a DT-757 terminal board, and processed by a computer using a Labtech Notebook data acquisition program. Each night, up to six individuals were studied simultaneously. We consistently used at least two different species, as well as variable fasting times, each night. After arousal of the birds, which usually occurred between 06:00 and 07: 00 , they were removed from their cages and released again after removing the thermocouples and re-weighing.

The total time spent in torpor during a night was calculated as the time $T_{b}$ was below $35^{\circ} \mathrm{C}$ during that particular night. Mean body temperature during torpor was only calculated if a stable value had been attained. 
All statistics were carried out using SigmaStat software (ver. 1.0, Jandel Scientific). Results are given as the mean $\pm \mathrm{SD}$. Statistical significance was set at $P<0.05$.

\section{RESULTS}

A total of 22 Amazilia versicolor, 29 Melanotrochilus fuscus and 27 Eupetomena macroura were tested for one night. Of these, 16, 10 and 12 individuals, respectively, went into torpor. There were marked variations in the pattern, as well as the likelihood, of entering torpor and the duration of torpor among individuals and species. In M. fuscus, those individuals entering torpor had a significantly lower body mass at roosting time compared to those individuals that did not enter torpor (Table 1). Thus whether this species entered torpor during a particular night clearly depended upon the evening body mass, and hence their energy reserves. In contrast, evening body mass was not associated with torpor in A. versicolor and $E$. macroura ( $t$-tests, $P$ $=0.09$ and $P=0.80$, respectively; Table 1 ). In all three species the use of torpor resulted in a significant reduction in overnight mass loss compared to birds not in torpor (Table 1). There was a marked difference between $M$. fuscus and the other two species in the duration of torpor periods. Long torpor periods, lasting throughout the entire night, were regularly found in $M$. fuscus, whereas shorter torpor periods, sometimes less than $1 \mathrm{hr}$, were observed in the other two species (Fig. 1). In both $A$. versicolor and $E$. macroura, total torpor time during a night varied between 2 and $11 \mathrm{hr}$, whereas in $M$. fuscus the torpor periods were always long (7.5-11 hr).

In all three species of hummingbirds we observed an unusual pattern of torpor with more than one torpor bout during a single night (Fig. 1). This pattern of torpor mostly was seen in $A$. versicolor, in which up to three distinct torpor bouts could be recorded during a single night (Fig. 1). Such a multiple torpor pattern was observed in 4 of the 16 torpid $A$. versicolor, in 1 of the 10 torpid $M$. fuscus, and 1 of the 12 torpid E. macroura.

The mean nocturnal body temperatures of the hummingbirds when in a non-torpid state were $36.8 \pm 1.3^{\circ} \mathrm{C}(n=22)$ for $A$. versicolor, $37.3 \pm$ $1.5^{\circ} \mathrm{C}(n=25)$ for $M$. fuscus, and $37.1 \pm 1.3^{\circ} \mathrm{C}$ $(n=27)$ for $E$. macroura. None of these means were different (one way ANOVA, $F_{271}=0.57$, $P>0.5$ ). During torpor the body temperature

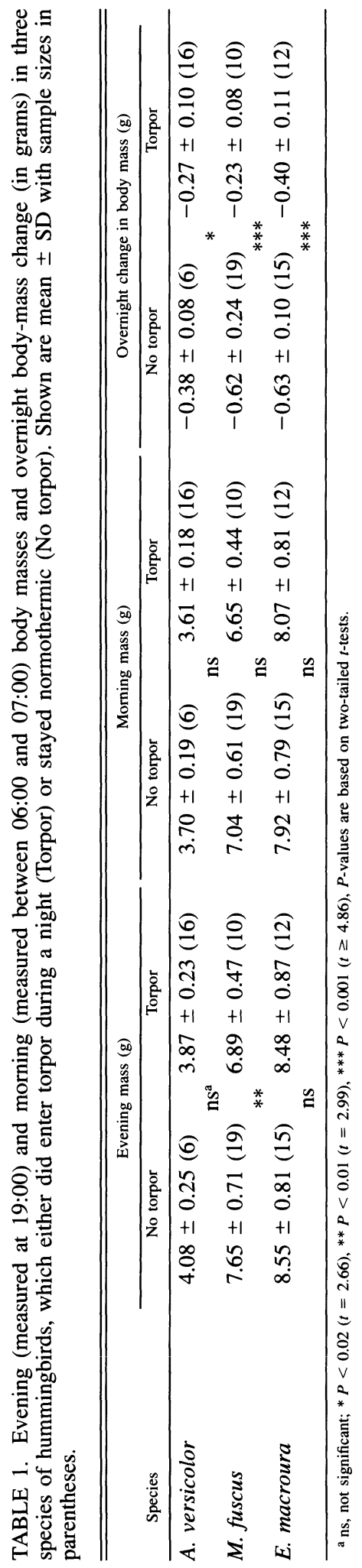




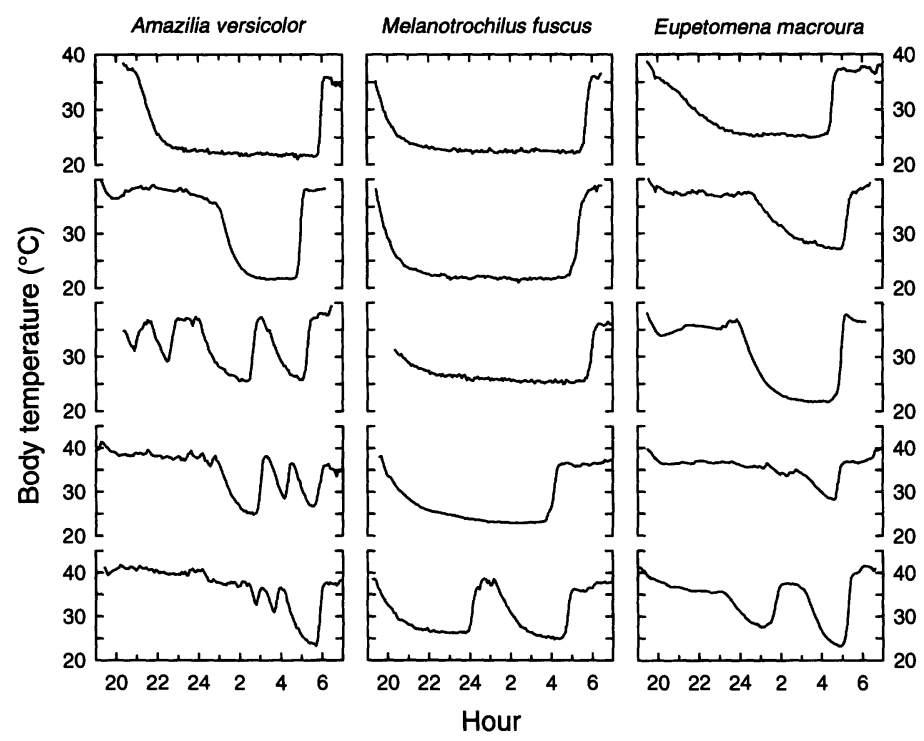

FIGURE 1. Representative examples of body temperature measured in individuals of Amazilia versicolor, Melanotrochilus fuscus, and Eupetomena macroura entering torpor. Note the occurrence of multiple torpor bouts in several of the individuals. Line based on mean values calculated for every seven measurements (every 280 sec).

was regulated at a level close to the ambient temperature, with mean values of $23.8 \pm 1.4^{\circ} \mathrm{C}$ $(n=13), 24.7 \pm 1.7^{\circ} \mathrm{C}(n=12)$, and $23.2 \pm$ $1.4^{\circ} \mathrm{C}(n=11)$ for $A$. versicolor, $M$. fuscus and $E$. macroura, respectively. These values correspond to body-to-ambient temperature differences of $2.4 \pm 0.8^{\circ} \mathrm{C}, 3.2 \pm 0.8^{\circ} \mathrm{C}$, and $2.4 \pm$ $1.2^{\circ} \mathrm{C}$, respectively. The mean body temperatures during torpor and the body-to-ambient

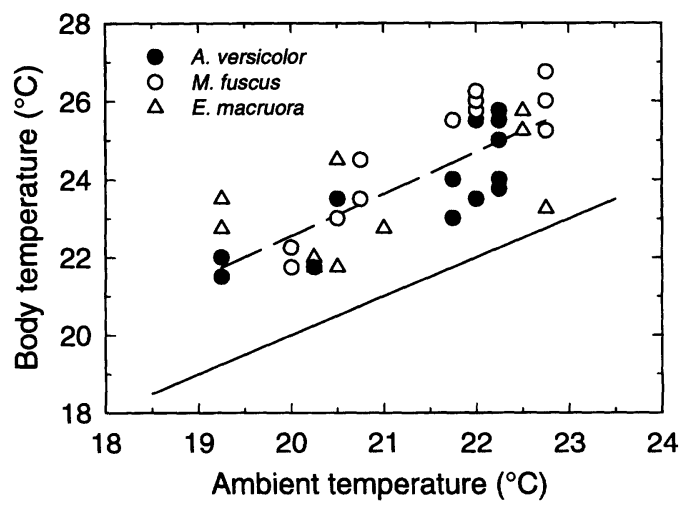

FIGURE 2. Body temperature of three species of hummingbirds during torpor, as a function of ambient temperature. Solid line shows $\mathrm{T}_{b}=\mathrm{T}_{\mathrm{a}}$; the broken line shows the linear regression line obtained for all the $\mathrm{T}_{\mathrm{b}}$ values: $\mathrm{T}_{\mathrm{b}}=1.05+1.08 \mathrm{~T}_{\mathrm{a}}(r=0.77, P<0.05, n=$ 36). temperature differences between the three species approached significance $\left(F_{2,33}=2.98, P=\right.$ 0.06 , and $F_{2,33}=3.05, P=0.06$, respectively), suggesting that $M$. fuscus kept a slightly higher body temperature during torpor. The overall mean body-to-ambient temperature difference was $2.6 \pm 1.0^{\circ} \mathrm{C}$ ( $n=36$, Fig. 2 ). The relative constancy of this difference is best illustrated by those individuals experiencing sudden temperature changes during the recording. During one particular night there was a heavy rainstorm that lowered the ambient temperature by about $2^{\circ} \mathrm{C}$. This caused the body temperatures of the torpid birds to change in parallel (Fig. 3).

As an index of overnight energy expenditure, we calculated the mean overnight body-mass loss (BML). The overnight BML (expressed as a percentage of the initial body mass lost per hour during the night) decreased in all three species with the use of torpor (Fig. 4 and Table 1). In $A$. versicolor there also was a decrease in nocturnal energy expenditure with increasing fasting time (FT) before sunset. This relationship is described by the equation: $\mathrm{BML}=0.779-$ 0.003FT ( $r=0.70, n=15, P<0.05$; Fig. 4). Interestingly, even those individuals that did not enter torpor but remained normothermic throughout the night, showed a decrease in noc- 


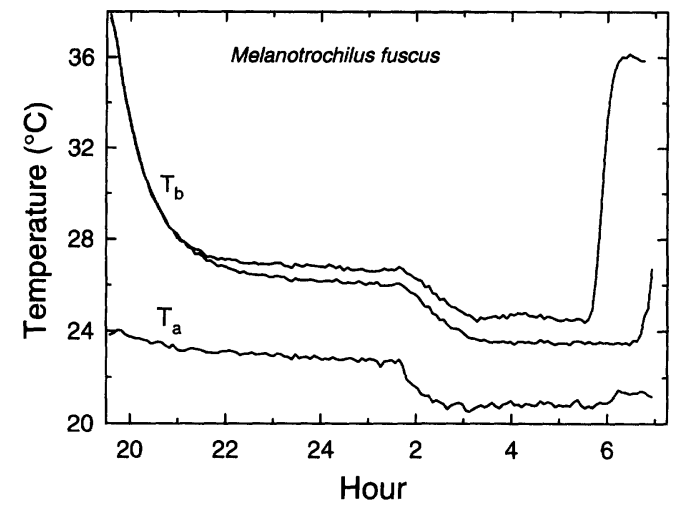

FIGURE 3. Ambient and body temperatures of two Melanotrochilus fuscus throughout a single night. The sudden drop in ambient temperature at 01:40 was due to heavy rain.

turnal energy expenditure with increasing fasting time. This relationship was statistically significant for $M$. fuscus (BML $=0.934-0.003 \mathrm{FT}$, $r=0.78, n=19, P<0.001)$ and $E$. macroura $(\mathrm{BML}=0.675-0.001 \mathrm{FT}, r=0.57, n=15, P$ $<0.05$; Fig. 4). A similar relationship could not be demonstrated for $A$. versicolor, probably because too few individuals failed to enter into torpor (Fig. 4). Because of this relationship between BML and fasting time in non-torpid $E$. macroura and $M$. fuscus, there may be a relationship between non-torpid body temperatures and BML. This was in fact the case for E. $m a$ croura, in which there was a significant positive relationship between nocturnal non-torpid body temperature and overnight body-mass loss $\left(\mathrm{BML}=0.627+0.0327 \mathrm{~T}_{\mathrm{b}}, r=0.46\right.$, one-tailed $t$-test, $\left.t_{14}=1.86, P<0.05\right)$. In $M$. fuscus there was, however, no such relationship.

In the smallest species (A. versicolor), torpor occurred even in one individual that was allowed to feed up to the time of sunset (Fig. 4). It seems that $A$. versicolor is less tolerant of fasting stress than the two other larger hummingbird species, which could remain normothermic throughout the night even after fasting for almost three hours (Fig. 4). However, for all three species, the saving of energy achieved by entry into torpor is reflected in lower overnight body-mass loss compared to those which did not enter torpor. This also is manifested in Figure 5, which shows that the overnight mass loss was correlated, negatively and significantly, with the total time spent in torpor during the night.

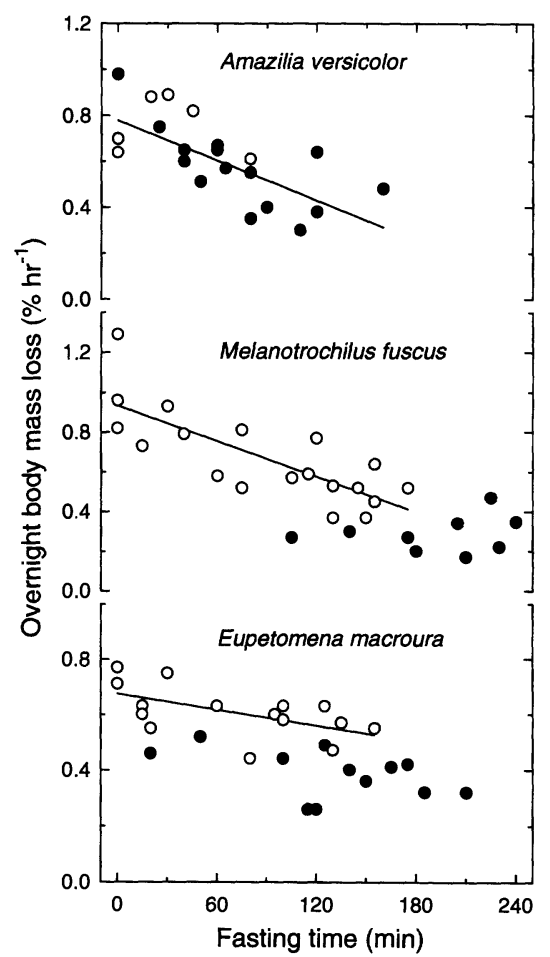

FIGURE 4. Overnight body mass loss (\% decrease in body mass $\cdot \mathrm{hr}^{-1}$ ) in three species of hummingbirds as a function of fasting time before sunset. Open circles indicate birds that were normothermic $\left(\mathrm{T}_{\mathrm{b}}\right.$ above $35^{\circ} \mathrm{C}$ ) throughout the night, and filled circles signify hummingbirds that entered torpor for a period of variable duration. Lines signify significant relationships (for equations: see text). For two individuals (one $A$. versicolor and one $M$. fuscus) we did not record the accurate time of food deprivation prior to sunset, and the number of individuals consequently do not correspond to the number of individuals from which body mass recordings were obtained (Fig. 5).

As BML is an indirect measure of energy expenditure, the energy saved by entry into torpor can be calculated using the regression lines relating overnight mass loss to torpor duration (Fig. 5). Using these regression lines, we calculated the decrease in overnight body-mass loss (assumed to correspond to the change in energy expenditure) associated with a torpor period of 10 hours out of a total night of 11 hours. The results indicated a mean nightly energy savings of $49 \%$ for $A$. versicolor, $61 \%$ for $M$. fuscus, and $60 \%$ for E. macroura.

\section{DISCUSSION}

The present results indicate that, at the prevailing ambient temperatures, a nonregulated torpor 


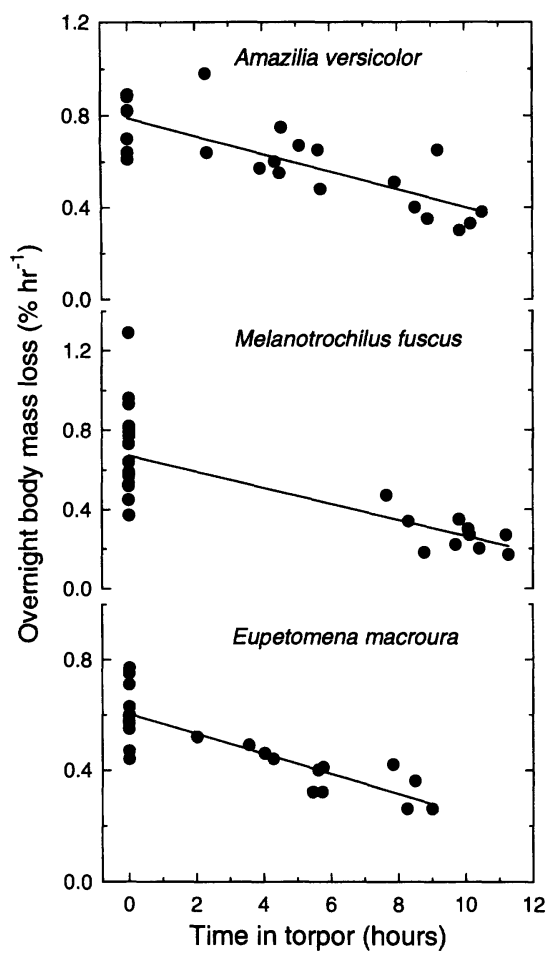

FIGURE 5. Overnight body mass loss (\% decrease in body mass $\cdot \mathrm{hr}^{-1}$ ) in three species of hummingbirds as a function of the time spent in torpor. The overnight body mass losses (BML) expressed as a function of torpor time (TT) are described by the following equations: $\mathrm{BML}=0.790-0.039 \mathrm{TT}(r=0.78, P<0.05$, $n=22)$ for Amazilia versicolor; $\mathrm{BML}=0.671-$ $0.041 \mathrm{TT}$ ( $r=0.71, P<0.05, n=29$ ) for Melanotrochilus fuscus; and BML $=0.604-0.036 \mathrm{TT}(r=0.85$, $P<0.05, n=27$ ) for Eupetomena macroura.

occurred in all three hummingbird species. Thus $T_{b}$ was not regulated at the lowest level. Our unpublished data, based on metabolic studies at ambient temperatures experimentally lowered below that of the outside conditions, indicate that $M$. fuscus regulates its $\mathrm{T}_{\mathrm{b}}$ at $19-23^{\circ} \mathrm{C}$, and $E$. macroura regulates its $\mathrm{T}_{\mathrm{b}}$ at $13-16^{\circ} \mathrm{C}$ during torpor. We have no equivalent data for $A$. versicolor, but for five other species of hummingbirds (Lophornis magnifica, Calliphlox amethystina, Clytolaema rubricauda, Leucochloris albicollis, and Phaethornis pretrei) from the same area in Brazil, the regulated body temperatures recorded during torpor range between 12 and $18^{\circ} \mathrm{C}$ (unpubl. data). Thus, at ambient temperatures of between 19 and $23^{\circ} \mathrm{C}$, as encountered in the present study, the hummingbirds apparently were not exposed to temperatures low enough to elicit a regulation of $T_{b}$ (Fig. 2). The nightly energy savings (49-61\% of potential nightly energy expenditure) resulting from using torpor at these ambient temperatures falls within the same range as previously reported for other hummingbirds (Krüger et al. 1982, Wang 1989).

Entry into torpor clearly depended upon the hummingbirds' energetic state (the duration of fasting time before sunset), and supports the general view that torpor in hummingbirds is a mechanism normally evoked as a response to energy stress (Hainsworth et al. 1977). This also accords with findings in many other species of birds in which a nightly hypothermia has been described as a response to energy stress (Biebach 1977, Reinertsen and Haftorn 1984, Graf et al. 1989). Interestingly, the present study has revealed that, in $M$. fuscus and $E$. macroura, those individuals that did not resume a torpid state during the night, but suffered from a long fasting period before dusk, could decrease their overnight energy expenditure (Fig. 4). In E. macroura this was paralleled by a decrease in $T_{b}$ as well. Thus, even before hummingbirds reach the body mass threshold for torpor initiation they may enter a low metabolic/low $T_{b}$ state, which may qualitatively be similar to the nightly hypothermia seen in other groups of birds. The body temperatures $\left(36.8-37.3^{\circ} \mathrm{C}\right)$ observed when hummingbirds were resting at night in a nontorpid state are within the range of nightly body temperatures previously reported in hummingbirds (35.3-39.5 $\mathrm{C}$; Prinzinger et al. 1991).

In addition to the use of torpor as a defense mechanism against energy stress, some studies have indicated that hummingbirds also may enter into torpor during presumably normal nonstressed periods (Krüger et al. 1982). Carpenter and Hixon (1988) showed that the Rufous Hummingbird may become torpid during the premigratory period, apparently in order to enable a more rapid build up of fat reserves. This recently has been supported by further studies (Carpenter et al. 1993, Hiebert 1993a, 1993b). Carpenter (1974) reported torpor in the Andean Hillstar Hummingbird Oreotrochilus estella during natural roosting conditions, and found a clear seasonal difference in the use of torpor; both the number of incidences and the duration of the torpor periods were greater during the winter. Carpenter (1974) concluded that neither the ambient temperature nor low food availability could explain the use of torpor by this species. 
In the Poorwill (Phalaenoptilus nuttalli), daily torpor also may occur in free-ranging individuals independent of their energetic state (Brigham 1992). The results of the present study complement the above observations with the Versicolored Emerald Hummingbird A. versicolor, which may undergo nightly torpor during periods of apparently high food availability, as was indicated by the use of torpor in an individual caught at normal roosting time (Fig. 4). For the other two species studied, a fasting period seemed to be necessary for the induction of torpor. The shortest time of food deprivation necessary to induce torpor in $M$. fuscus and $E$. $m a$ croura was 100 and $20 \mathrm{~min}$, respectively (Fig. 4). Thus, our data suggest that $E$. macroura also has the ability to enter torpor under normal, nonstressed circumstances. $M$. fuscus, on the other hand, seems to be less prone to enter torpor, since torpor was not recorded even after fasting periods of up to $100 \mathrm{~min}$ duration before dusk (Fig. 4). Heavy rain or cold weather probably could hinder hummingbirds in feeding for a period before dusk, and it is conceivable that periods of food-deprivation of up to 100 minutes could indeed occur under normal circumstances in the study area. There are no apparent interspecific differences in the biology of the three species which could explain the observed differences in torpor pattern.

The three species of hummingbirds used in the present study were able to enter torpor more than once during a single night (Fig. 1; see also Bech et al. 1994). This implies that some of the single torpor periods were short duration, lasting for only a few hours. Hainsworth et al. (1977) also reported torpor periods of only $2.5 \mathrm{hr}$ in Rivoli's Hummingbird Eugenes fulgens and 3.5 $\mathrm{hr}$ in the Black-chinned Hummingbird Archilochus alexandri, whereas Hiebert (1990) showed that torpor bouts of 2.5-3.0 hr could occur late in the night in Rufous Hummingbirds. Thus, most.hummingbirds may have the ability to enter torpor for short periods at a time. However, the present description of multiple periods of torpor in hummingbirds would seem to be the first report of such cases. We cannot offer any explanation as to the cause of such a pattern, which seems to conflict with the assumption that there is a minimum body mass (set-point) below which the hummingbird is obliged to enter torpor (Hainsworth et al. 1977). However, in contrast to most other (laboratory) studies on torpor in hummingbirds, the birds in the present study were exposed to natural photoperiod, temperature and sounds. Thus, it is likely that the multiple torpor bouts could be related to the experimental conditions. Any external sound stimuli from the tropical night could have initiated arousal. However, we never detected any obvious external stimuli that occurred during the nights on which we observed multiple bouts of torpor. In addition, often only one of the individuals studied during a single night would exhibit multiple torpor bouts, while the others had either one long period, or did not enter torpor at all. This obviously could stem from differences in energetic state and different levels of susceptibility to external stimuli. Regardless of the reason for multiple nightly torpor bouts, further studies employing hummingbirds in their natural habitat are needed to establish how widespread this pattern is. Most earlier studies were conducted on hummingbirds with lower body temperatures during torpor. Assuming a gradual loss of response with body temperature, the relatively high $\mathrm{T}_{\mathrm{b}}$ during torpor in the tropical hummingbird species of the present study might cause a higher degree of susceptibility to external stimuli, in contrast to hummingbirds from temperate and montane areas, which often have lower levels of torpor body temperatures (5$10^{\circ} \mathrm{C}$; Calder and Booser 1973, Calder 1974, Carpenter 1974).

When hummingbirds experienced these interrupted torpor periods, they would invariably enter torpor again after having reached the normothermic nightly $T_{b}$ level (Fig. 1). This still lends credit to the theory that a threshold-value of body mass is operating (Hainsworth et al. 1977, Hiebert 1992). The observation of multiple torpor bouts, on the other hand, raises a fundamental question about the energetics of torpor, namely whether the individuals will still have an energetic advantage from such very short torpor bouts. Our results indicate that some individuals may not even utilize the full time required to enter torpor, but may actually arouse from torpor before their body temperature has reached its lowest level. Thus, $T_{b}$ only was lowered to $a$ value between the normothermic and normal torpid values (A. versicolor, Fig. 2). However, our data do not allow us to test whether such very short periods of torpor are of thermoregulatory significance to the birds. The hummingbirds would benefit from these torpor bouts if the cost 
of arousal would not counteract the, even short-term, reduction in body temperature and metabolic rate. Recent data obtained from both hummingbirds (Hiebert 1990) and mammals (Ruf and Heldmaier 1992) seem to indicate that homeotherms will in fact benefit energetically from any torpor bout regardless of its length.

In summary, we have shown that there are large interspecific differences in the use of torpor between the three Brazilian hummingbird species studied. Whereas $A$. versicolor and $E$. macroura seem to enter torpor very readily without any previous energy stress, $M$. fuscus apparently only enter torpor when energetically stressed (low body mass). The reason for these differences is unknown. All three species will at times have multiple torpor bouts during the night. We suggest that this is caused by interruption of the normal torpor period by external stimuli.

\section{ACKNOWLEDGMENTS}

The study was initiated by the late Kjell Johansen. Financial support was generously provided by the Erna and Victor Hasselblads Stiftelse (to KJ and JFS), Ib Henriksens Fond (to KJ and JFS), the Danish Natural Science Research Council (to KJ and JFS), and the Deutsche Forschungsgemeinschaft (grant Be $536 \mathrm{tc}$ MB). We also wish to thank the Brazilian National Research Council (CNPq) for its support (grants to ASA, JFS and JEPWB) and for permission to carr: out this study in Brazil (permit no. EX-16/87). Thanks also are due to the staff at the Museu de Biologia Prof Mello Leitao in Santa Teresa for their invaluable support during our stay. We are grateful to Philip A. Tallantire and Stephen H. Clayborough for correcting the language and two referees for valuable suggestions on the manuscript.

\section{LITERATURE CITED}

Bech, C., A. S. Abe, J. F. Steffensen, M. Berger, And J. E. P. W. BicuDo. 1994. Multiple nightly torpor bouts in hummingbirds, p. 323-328. In $\mathrm{K}$. Plesch$\mathrm{ka}$ and $\mathrm{R}$. Gerstberger [eds.], Integrative and cellular aspects of autonomic function: temperature and osmoregulation. John Libbey Eurotext, Paris.

$\rightarrow$ Beuchat, C. A., S. B. Chaplin, and M. L. Morton. 1979. Ambient temperature and the daily energetics of two species of hummingbirds, Calypte anna and Selasphorus rufus. Physiol. Zool. 52: 280-295.

$\rightarrow$ BIEBACH, H. 1977. Reduktion des Energiestoffwechsels und der Körpertemperatur hungernder Amseln (Turdus merula). J. Ornithol. 118:294-300. $\rightarrow$ Brigham, R. M. 1992. Daily torpor in a free-ranging
goatsucker, the Common Poorwill (Phalaenoptilus nuttallii). Physiol. Zool. 65:457-472.

Calder, W. A. 1974. Consequences of body size fo $\rightarrow$ Prinzinger, R., A. Pressmar, and E. Schleucher. avian energetics. Publ. Nuttall Ornithol. Club 15: 86-144.

CALDER, W. A. 1994. When do hummingbirds use torpor in nature? Physiol. Zool. 67:1051-1076.

CALDER, W. A., AND J. Booser. 1973. Hypothermia of Broad-tailed Hummingbirds during incubation in nature with ecological correlations. Science 180:751-753.

Calder, W. A., L. L. Calder, and T. D. Frazier. 1990. The hummingbird's restraint: a natural model for weight control. Experientia 46:9991002.

CARPENTER, F. L. 1974. Torpor in an Andean hummingbird: its ecological significance. Science 183: 545-547.

Carpenter, F. L., and M. A. Hixon. 1988. A new function for torpor: fat conservation in a wild migrant hummingbird. Condor 90:373-378.

Carpenter, F. L., M. A. Hixon, C. A. Beuchat, R. W. Russell, AND D. C. PATON. 1993. Biphasic mass gain in migrant hummingbirds: body composition changes, torpor, and ecological significance. Ecol-

FRENCH, A. R. 1993. Hibernation in birds: comparison with mammals, p. 43-53. In C. Carey, G. L. Florant, B. A. Wunder, and B. Horwitz [eds.], Life in the cold: ecological, physiological and molecular mechanisms. Westview Press, Boulder, CO.

Graf, R., S. Krishna, AND H. C. Heller. 1989. Regulated nocturnal hypothermia induced in pigeons by food deprivation. Am. J. Physiol. 259:R733R738.

Hainsworth, F. R., B. G. Collins, and L. L. Wolf. 1977. The function of torpor in hummingbirds. Physiol. Zool. 50:215-222.

HAINSWORTH, F. R., M. F. TARDIFF, AND L. L. Wolf. 1981. Proportional control for daily energy regulation in hummingbirds. Physiol. Zool. 54:452462.

HelleR, H. C. 1989. Sleep, hypometabolism, and torpor in birds, p. 231-245. In C. Bech and R. E. Reinertsen [eds.], Physiology of cold adaptation in birds. Plenum Press, New York.

$\rightarrow$ Hiebert, S. M. 1990. Energy costs and temporal organization of torpor in the Rufous Hummingbird (Selasphorus rufus). Physiol. Zool. 63: 1082-1097.

HIEBERT, S. M. 1992. Time-dependent thresholds for torpor initiation in the Rufous Hummingbird ( $\mathrm{Se}$ lasphorus rufus). J. Comp. Physiol. 162:249-255.

HIEBERT, S. M. 1993a. Seasonal changes in body mass and use of torpor in a migratory hummingbird. Auk 110:787-797.

HIEBERT, S. M. 1993b. Seasonality of daily torpor in a migratory hummingbird, p. 25-32. In C. Carey, G. L. Florant, B. A. Wunder, and B. Horwitz [eds.], Life in the cold: ecological, physiological and molecular mechanisms. Westview Press, Boulder, CO.

Krüger, K., R. Prinzinger, and K.-L. Schuchmann. 1982. Torpor and metabolism in hummingbirds. Comp. Biochem. Physiol. 73A:679-689. ogy 74:1173-1182. 
1991. Body temperature in birds. Comp. Bio $\rightarrow$ RUF, T., AND G. HeldMaIER. 1992. The impact of daily chem. Physiol. 99B:499-506.

REINERTSEN, R. E. 1983. Nocturnal hypothermia and its energetic significance for small birds living in the arctic and subarctic regions. A review. Polar Res. 1:269-284.

REINERTSEN, R. E., AND S. HAFtorn. 1984. The effect of short-time fasting on metabolism and nocturnal hypothermia in the Willow Tit Parus montanus. J. Comp. Physiol. 154:23-28. torpor on energy requirements on the Djungarian hamster, Phodopus sungorus. Physiol. Zool. 65: 994-1010.

RusCHI, A. 1982. Hummingbirds of state of Espirito Santo. Editora Rios, Sao Paulo, Brazil.

WANG, L. C. H. 1989. Ecological, physiological, and biochemical aspects of torpor in mammals and birds, p. 361-401. In L. C. H. Wang [ed.], Advances in comparative and environmental physiology, Vol. 4. Springer-Verlag, Berlin. 